\title{
Lyme Neuroborreliosis
}

\author{
Sebastian Rauer, Stefan Kastenbauer, Volker Fingerle, Klaus-Peter Hunfeld, Hans-lko Huppertz, \\ and Rick Dersch for the guideline group*
}

\begin{abstract}
Summary
Background: The new German S3 guideline on Lyme neuroborreliosis is intended to provide physicians with scientifically based information and recommendations on the diagnosis and treatment of this disease.

Methods: The scientific literature was systematically searched and the retrieved publications were assessed at the German Cochrane Center (Deutsches Cochrane Zentrum) in Freiburg in the 12 months beginning in March 2014. In addition to the main search terms "Lyme disease," "neuroborreliosis," "Borrelia," and "Bannwarth," 28 further terms relating to neurological manifestations of the disease were used for the search in the Medline and Embase databases and in the Cochrane Central Register of Controlled Trials.
\end{abstract}

Results: In the treatment of early Lyme neuroborreliosis, orally administered doxycycline is well tolerated, and its efficacy is equivalent to that of intravenously administered beta-lactam antibiotics (penicillin $\mathrm{G}$, ceftriaxone, and cefotaxime) (relative risk [RR]: 0.98, 95\% confidence interval [CI]: [0.68; 1.42], $P=0.93$ ). 14 days of treatment suffice for early Lyme neuroborreliosis, and 14-21 days of treatment usually suffice for late (chronic) Lyme neuroborreliosis.

Conclusion: Lyme neuroborreliosis has a favorable prognosis if treated early. The long-term administration of antibiotics over many weeks or even months for putative chronic Lyme neuroborreliosis with nonspecific symptoms yields no additional benefit and carries the risk of serious adverse effects.

\section{Cite this as:}

Rauer S, Kastenbauer S, Fingerle V, Hunfeld KP, Huppertz HI, Dersch R: Clinical practice guideline: Lyme neuroborreliosis. Dtsch Arztebl Int 2018; 115 : 751-6. DOI: 10.3238/arztebl.2018.0751
Department of Neurology and Neurophysiology, Medical Center-University of Freiburg: Prof. Dr. med. Sebastian Rauer, Dr. med. Rick Dersch

Neurologische Praxis, München: PD Dr. med. Stefan Kastenbauer

National Reference Centre for Borrelia, Bavarian Health and Food Safety Authority, Oberschleissheim: Dr. med. Volker Fingerle

Institute for Laboratory Medicine, Microbiology and Hospital Hygiene, Krankenhaus Nordwest, Frankfurt/Main: Prof. Dr. med. Klaus-Peter Hunfeld, MPH

Klinikum Bremen Mitte, Prof.-Hess-Kinderklinik and Clinic for Pediatric Intensive Care, Bremen: Prof. Dr. med. Hans-lko Huppertz

Evidence in Medicine / Cochrane Germany, Medical Center, Faculty of Medicine, University of Freiburg: Dr. med. Rick Dersch

${ }^{*}$ All of the editors, authors, and processors of the German S3 guideline on Lyme neuroborreliosis are listed in the eBox.
T he scientists and physicians involved in research on Lyme neuroborreliosis agree that this disease can be reliably diagnosed and permanently stopped with a two- to three-week course of antibiotic treatment. There nonetheless exists a widespread fear that Lyme disease (as it is also called) can lead to a wide variety of nonspecific symptoms, such as chronic pain, fatigue, and difficulty concentrating, despite antibiotic treatment. This view often leads to repeated courses of antibiotic treatment being given for several months at a time, sometimes with serious adverse effects; there have even been a few deaths (e1-e3). The objective of the S3 guideline on Lyme neuroborreliosis issued by the German Society of Neurology (Deutsche Gesellschaft für Neurologie) is, therefore, to provide clear recommendations on the diagnosis and treatment of this disease which are based on a structured evidence and consensus process.

\section{Epidemiology}

Lyme borreliosis is an infectious disease that manifests itself primarily on the skin, in the nervous system, and in the joints. Five species of Borrelia burgdorferi that are pathogenic for human beings have been identified as the responsible organisms in Europe; they are transmitted by the bite of Ixodes ricinus, a species of hard tick. The number of new cases in Germany each year is variably estimated from 60000 to over 200000 (e4, $\mathrm{e} 5)$, in the absence of precise figures. The seroprevalence of Borrelia-specific antibodies in healthy persons ranges from $5 \%$ to $20 \%$, depending on their age and place of residence (e6-e8). According to German surveys, tick bites lead to seroconversion in $2.6 \%-5.6 \%$ of cases, and to overt disease in $0.3-1.4 \%$ (e9-e11).

\section{Method}

The first step in the creation of the guideline was a search for, and an assessment of, already existing guidelines on the subject, of which eight were found. Structured evaluation revealed that all of them had low quality scores, with the result that none of their recommendations could be adopted without further investigation (1). To assess the various proposed modes of antibiotic treatment, systematic literature searches were carried out in three databases:

- Medline (via Ovid),

- Embase (via Scopus),

- and the Cochrane Central Register of Controlled Trials.

Each included study was assessed in structured fashion $(2,3)$. The results for all of the included 


\section{Diagnostic criteria for Lyme neuroborreliosis (4)}

\section{- Possible Lyme neuroborreliosis}

- typical clinical features (cranial nerve deficits, meningitis/meningoradiculitis, focal neurological deficits)

- Borrelia-specific IgG and or IgM antibodies in the serum (in very early stages of the disease, the serology may not [yet] be positive)

- CSF findings unavailable, or no lumbar puncture performed

- exclusion of other possible causes

\section{- Probable Lyme neuroborreliosis}

as in possible Lyme neuroborrelosis (above) and, additionally:

- inflammatory CSF syndrome with lymphocytic pleocytosis, blood-CSFbarrier disruption, and intrathecal immunoglobulin synthesis

\section{- Definite Lyme neuroborreliosis}

as in probable Lyme neuroborreliosis (above) and, additionally:

- intrathecal synthesis of Borrelia-specific antibodies (positive lgG and/or IgM antibody index in CSF) or

- positive Borrelia detection by culture or by nucleic acid demonstration via polymerase chain reaction (PCR) in CSF

studies (reported as stipulated by the PRISMA statement, i.e., Preferred Reporting Items for Systematic Reviews and Meta-Analyses) are shown in the Figure (4). Further procedural details are described in the eMethods section.

\section{Clinical features Neurological manifestations in adults}

Polyradiculitis, i.e., inflammation that affects multiple spinal nerve roots and/or cranial nerves, is the most common clinical manifestation of neuroborreliosis in adults. If the meninges are (latently) involved as well, this is called meningoradiculoneuritis (GarinBujadoux-Bannwarth syndrome, or Bannwarth syndrome for short), which, after erythema migrans (EM), is the second most common manifestation of Lyme borreliosis among adults in Europe (5-7). Only 25-50\% of patients with Lyme neuroborreliosis have a history of EM, and only a third have a history of tick bite (5-7, $\mathrm{e} 12, \mathrm{e} 13)$.

Bannwarth syndrome typically manifests itself with severe, zoster-like segmental pain that is worse at night, responds poorly if at all to common painrelieving drugs, and has a burning, stabbing, biting, or tearing character. $75 \%$ of patients develop neurologic deficits in 1-4 weeks, generally in the form of a flaccid paralysis or a segmental sensory disturbance. Cranial nerve deficits arise in roughly $60 \%$ of patients with Bannwarth syndrome. In more than $80 \%$ of such cases, facial nerve involvement leads to a typical peripheral facial palsy (which is bilateral in one-third of cases). In principle, any of the other cranial nerves could be affected as well, although no case of olfactory nerve involvement has yet been reported $(5$, $6,8)$.

Infection of the central nervous system is seen in $2-4 \%$ of all cases of Lyme neuroborreliosis, typically in the late or chronic stage of the disease $(5,6)$. Its onset is often insidious, with a tendency to worsen slowly over a period of months to years. The spinal cord is the most commonly affected part of the CNS, with myelitis manifesting itself in a spastic-ataxic gait and bladder dysfunction; the brain is affected (encephalitis) in $60 \%$ of cases, with additional cranial nerve involvement in $40 \%(6,7)$.

In European patients, polyneuropathy/polyneuritis is generally seen only in association with acrodermatitis chronica atrophicans (ACA) as a manifestation of borreliosis $(9,10)$. The mere fact that a patient has polyneuropathy/polyneuritis and positive Borrelia serology in the blood does not, in itself, imply a causal relationship between the neurological manifestations and a putative Borrelia infection (11), as Borrelia-specific antibodies can be found in 5-20\% of normal individuals, depending on the endemic area and age group (e6, e8, e13).

Rarely, encephalitis manifests itself as a mental illness or organic brain syndrome $(5,12, \mathrm{e} 14-\mathrm{e} 17)$ with inflammatory changes in the cerebrospinal fluid that resolve under treatment with antibiotics.

Stroke has also been described in case reports and small case series, as a result of Borrelia-induced cerebral vasculitis (e18, e19). Another very rare manifestation is Borrelia-induced myositis, which has only been described in older single-case reports (e20, e21).

\section{Neurological manifestations in children}

Among children in Europe, the most common manifestations are facial nerve palsy (ca. 55\%) and lymphocytic meningitis (ca. 30\%) $(13,14)$. Meningitis, when present, often has only very mild symptoms; it can easily be missed unless cranial nerve deficits are present at the same time (15). Late (chronic) Lyme neuroborreliosis is very rare in children (e22).

\section{Diagnostic evaluation}

If the clinical manifestations arouse the suspicion of Lyme neuroborreliosis, the serum and the CSF should be examined (16-18) $(\uparrow \uparrow)$. Inflammatory changes in the CSF (pleocytosis, disruption of the blood-CSF barrier, intrathecal immunoglobulin synthesis) are to be expected in every case of Lyme neuroborreliosis. Normal CSF is seen only in very early stages of the disease, or else in patients with distal symmetric polyneuropathy in association with ACA.

Borrelia-specific IgM antibodies are detectable in the blood from the third week after exposure, and IgG antibodies from the sixth. In late (chronic) Lyme neuroborreliosis, high Borrelia-specific IgG antibody concentrations should, in principle, always be found, as long as the patient is immune-competent $(17,19)$. However, antibody generation does not always take the typical course seen in other infectious diseases. 
For example, both IgG and IgM antibodies can persist for several years despite a clinically healed infection $(17,19)$. In consequence, a positive serological finding alone does not establish the presence of an infection. Serological testing should be ordered only if there is adequate clinical suspicion of active borreliosis, as its predictive value will otherwise be low

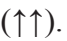

In most patients, CSF examination confirms the clinically suspected diagnosis by revealing the intrathecal synthesis of Borrelia-specific antibodies in association with an elevated CSF cell count $(17,20)$. It is, therefore, recommended that CSF and serum should be obtained simultaneously for serologic testing in any patient with suspected Lyme neuroborreliosis $(\uparrow \uparrow)$. CSF analysis should include cytological, protein-chemical, and serological examinations (determination of the antibody index, AI) $(\uparrow \uparrow)$. The intrathecal production of Borreliaspecific antibodies is demonstrated by measurement of the Borrelia-specific CSF/serum antibody index (Borrelia-specific AI) $(7,21)$.

If the diagnosis remains unclear, e.g., in an immunosuppressed patient, a suspected infection can be confirmed by detection of the pathogen in the CSF (17). The sensitivity of pathogen detection in the CSF by culture or by the polymerase chain reaction (PCR) in acute Lyme neuroborreliosis is, however, only $10-30 \%$ (17, 19).

\section{Diagnostic criteria for Lyme neuroborreliosis}

Algorithms for the diagnostic evaluation of early and late Lyme neuroborreliosis are shown in eFigures 1 and 2 (4). Depending on the clinical and laboratory findings, the diagnosis of Lyme neuroborreliosis can be classified as possible, probable, or definite $(4,16,22)$ (Box 1).

\section{Unsuitable diagnostic tests}

No prospective, controlled trials are available that would support the putative utility of the methods listed in Box 2 in the diagnostic evaluation of Lyme neuroborreliosis. These methods should, therefore, not be used for this purpose $(\downarrow \downarrow)$ (17).

\section{The treatment of Lyme neuroborreliosis}

A systematic evaluation of the literature on the pharmacotherapy of Lyme neuroborreliosis yielded only a limited amount of evidence overall (Figure) $(2,3)$. Conclusions for clinical practice can be drawn from no more than a few studies, some of which involved only a small number of patients, and some of which were vulnerable to bias (3). An update of the systematic literature search (method analogous to [2]) in August 2018 yielded 700 new results, of which only a single publication contained relevant information that met the inclusion criteria established for the current guideline (25). In this study, it was concluded that steroids have a statistically significant, deleterious effect on the regression of facial nerve palsies due to Lyme
BOX 2

\section{Unsuitable diagnostic tests for Lyme neuroborreliosis (4)}

- antigen detection in bodily fluids

- polymerase chain reaction on serum or urine samples

- lymphocyte transformation tests (LTT) (23)

- enzyme-linked immunospot assay (ELISPOT) (e23)

- xenodiagnosis: ixodid tick larvae are allowed to suck blood from a patient with suspected Lyme borreliosis and are then examined for Borrelia (e24, e25)

- Visual Contrast Sensitivity Test (VCS or gray shade test): the measurement of the patient's ability to recognize different shades of gray is held to indirectly demonstrate the effect of a lipophilic neurotoxin derived from Borrelia (e26)

- detection of so-called L forms or spheroplasts (24)

- detection of immune complexes as a marker of disease activity

- CD57-positive/CD3-negative lymphocyte subpopulation (e27)

- commercially available serological rapid tests (inadequate sensitivity [18-32\%]) (e28)

\section{FIGURE}

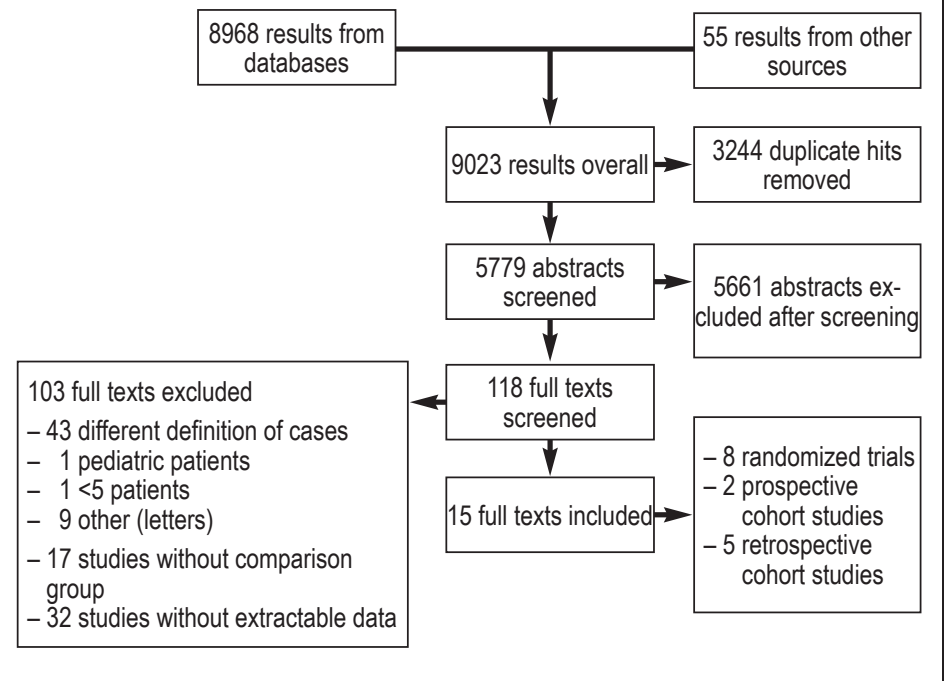

Flowchart of the included studies

neuroborreliosis. It must be remarked, however, that this particular study was based on a highly selected group of patients, the treatments and follow-up examinations were not standardized, and the retrospective design rendered the findings vulnerable to recruitment bias. It follows that no additional treatment recommendation can be derived from any data that were published after the initial literature review carried out in the preparation of this guideline. 
TABLE

Overview of antibiotic treatment (4)

\begin{tabular}{|c|c|c|c|}
\hline Antibiotic & $\begin{array}{l}\text { Adult dose } \\
\text { (dose/day) }\end{array}$ & $\begin{array}{l}\text { Pediatric dose } \\
\text { (dose/kg×day) }\end{array}$ & $\begin{array}{l}\text { Duratior } \\
\text { (days) }\end{array}$ \\
\hline \multicolumn{4}{|c|}{ Early Lyme neuroborreliosis } \\
\hline Doxycycline $^{* 1}$ & 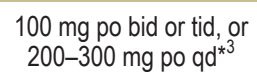 & $\begin{array}{l}\text { from age } 8,4 \mathrm{mg}^{\star 2} \\
\text { (maximum, } 200 \mathrm{mg} \text { ) }\end{array}$ & 14 \\
\hline Ceftriaxone & $2 \mathrm{~g}$ iv qd & $50 \mathrm{mg}$ & 14 \\
\hline Cefotaxime & $2 \mathrm{~g}$ iv tid & $100 \mathrm{mg}$ & 14 \\
\hline Penicillin G & 5 Mio IU iv qid & 200-500 000 IU & 14 \\
\hline \multicolumn{4}{|c|}{ Late Lyme neuroborreliosis } \\
\hline Ceftriaxone & $2 \mathrm{~g}$ iv qd & $50 \mathrm{mg}$ & $14-21$ \\
\hline Cefotaxime & $2 \mathrm{~g}$ iv tid & $100 \mathrm{mg}$ & $14-21$ \\
\hline Penicillin G & 5 Mio IU iv qid & 200-500 $000 \mathrm{IU}$ & $14-21$ \\
\hline Doxycycline $^{* 1}$ & 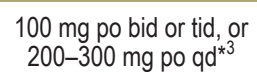 & $\begin{array}{l}\text { from age } 8,4 \mathrm{mg}^{* 2} \\
\text { (maximum, } 200 \mathrm{mg} \text { ) }\end{array}$ & $14-21$ \\
\hline
\end{tabular}

Any of the drugs listed above can be used; the optimal duration of treatment is unknown. Doxycycline should not be given to pregnant women.

*1 Optimal daily dose unknown. Note: the resorption of doxycycline can be impaired by bivalent or trivalent cations such as aluminum and calcium (contained in milk, dairy products, and calcium-rich fruit juices), magnesium in antacids, iron preparations, medical activated charcoal, and cholestyramine. Such medicines or foods should therefore not be taken less than 2-3 hours before or after any dose of doxycycline.

${ }^{*}$ after completed formation of dental enamel.

${ }^{*}$ for adolescents and adults weighing at least $50 \mathrm{~kg}$

bid, twice daily; IU, international units; iv, intravenously; po, by mouth; qd, (once) daily; qid, four times daily; tid, three times daily trolled trials in which antibiotic treatment for late (chronic) Lyme neuroborreliosis was explicitly studied. As far as was reported, the 17 systematically evaluated therapeutic trials (RCTs and NRS) contained a total of only 15 patients with late (chronic) Lyme neuroborreliosis (3). These cases cannot be separately evaluated, because of their small number and the incompleteness of the data. Although these patients had residual neurologic deficits much more commonly than those with early Lyme neuroborreliosis (class III), none of the reported cases showed evidence of being treatment failures. Thus, a risk/benefit analysis yields no scientifically supported reason to change the current recommendation for two to three weeks of antibiotic treatment for the typical patient with late (chronic) Lyme neuroborreliosis $(\uparrow \uparrow)$.

\section{The choice of antibiotic and side effects}

According to a meta-analysis, the efficacy of orally administered doxycycline with regard to the regression of neurological manifestations does not differ, to any statistically significant extent, from that of intravenously administered beta-lactam antibiotics, after a follow-up interval of 12 months (relative risk [RR]: $0.98,95 \%$ confidence interval $[\mathrm{CI}]:[0.68 ; 1.42]$, $\mathrm{P}=0.93$ ). They should thus be considered to be of comparable benefit (class Ia) (3). As for side effects, two RCTs $(26,27)$ did not show any statistically significant difference either (RR: $0.82[0.54 ; 1.25]$, $\mathrm{P}=0.35$ ) (class Ia). Serious side effects were reported too rarely overall in these trials to enable any valid comparison (3).

These data do not show any of the substances tested to be preferable to the others. An antibiotic should thus be chosen (Table) in consideration of patient-specific aspects such as allergies, age, pregnancy, and the mode and frequency of application $(\uparrow \uparrow)$.

\section{Clinical course after treatment with antibiotics}

In most of the RCTs, a 7- to 14-day course of antibiotic treatment for early Lyme neuroborreliosis led to marked improvement of neurologic manifestations in most patients within a few weeks to months. A year after treatment, approximately $90 \%$ of patients were free of symptoms $(6,28-30)$. Late Lyme neuroborreliosis can likewise be stabilized by one year after treatment, but $60-80 \%$ have relevant residual neurologic symptoms $(3,6,29)$.

\section{Cerebral vasculitis due to Lyme borreliosis}

Good results of early antibiotic treatment are reported in case series and narrative reviews (e18, e19) (class IV) ( $\uparrow)$. Some authors give steroids and platelet aggregation inhibitors in addition to antibiotics (class IV) $(\leftrightarrow)$.

\section{The treatment of Lyme neuroborreliosis in children}

A systematic evaluation of the literature reveals that there is only very limited evidence on the use of 
antibiotics to treat Lyme neuroborreliosis in children; furthermore, the available studies are of poor quality (31). All of them do, however, appear to document a favorable prognosis of Lyme neuroborreliosis in children. Unfavorable clinical courses under antibiotic treatment are rare, whatever antibiotic is used.

\section{Treatment monitoring}

The effect of treatment should be judged from the clinical manifestations. If the clinical situation worsens during or after treatment, the differential diagnosis should be rechecked in an interdisciplinary evaluation; if indicated, the CSF analysis should be repeated $(\uparrow \uparrow)$.

\section{Chronic atypical symptoms and "post-treatment Lyme disease syndrome"}

It has been debated for decades whether properly treated Lyme neuroborreliosis can transform itself into a chronic disease state with nonspecific symptoms, even in the absence of any inflammatory or infectious process that can be demonstrated by generally accepted methods of laboratory testing (32-34). Terms such as "post-treatment Lyme disease syndrome" (PTLDS), “(post-) Lyme encephalopathy," or simply "chronic (neuro-)borreliosis" have been used to describe such putative cases, without any clear differentiation in meaning from each other.

The frequency and symptom spectrum of chronic manifestations after antibiotic treatment for Lyme neuroborreliosis were systematically studied in a meta-analysis (35). Persistent general symptoms were found to be more common, to a markedly statistically significant extent, in patients whose initial diagnosis was not confirmed by CSF examination. This suggests that the high prevalence of nonspecific longterm symptoms found in earlier studies is perhaps best explained as an artifact induced by loose inclusion criteria.

The putative therapeutic benefit of antibiotics for patients with persistent nonspecific symptoms after (a correct or incorrect diagnosis of) chronic Lyme borreliosis-i.e., patients with so-called PTLDS or PTLDS-like symptoms - was studied in three randomized, placebocontrolled trials (36-39). No lasting improvement of neuropsychological test results was found in any trial. In two trials, no benefit was found with respect to either of two endpoints (fatigue and quality of life) $(36,37)$; in one trial, there was a slight, but statistically significant improvement of the fatigue score (38), but the clinical relevance of this finding seems questionable (e29) in view of the two negative trials $(36,37)$ and methodological considerations. Antibiotic side effects arose in all three trials, in $25-43 \%$ of the subjects. These included (among others) diarrhea, allergic reactions, cholecystitis, thromboembolism, and gastrointestinal bleeding. In three cases, antibiotic complications were life-threatening. None of the authors, in their risk/benefit analyses, recommended treating patients with so-called PTLDS or PTLDS-like symptoms with the antibiotic regimen that had been used in their own trial (36-39).

\section{Key messages}

- A clinically suspected diagnosis of Lyme neuroborreliosis (cranial nerve deficits, meningitis/meningoradiculitis, encephalomyelitis) can be confirmed by the demonstration of inflammatory CSF changes in association with the intrathecal synthesis of Borrelia-specific antibodies.

- Serologic testing should be ordered only when there is sufficient clinical suspicion.

- The antibiotic treatment of early and late Lyme neuroborreliosis should be with one of the following drugs: doxycycline, ceftriaxone, cefotaxime, and penicillin $\mathrm{G}$.

- The duration of antibiotic treatment should be 14 days for early Lyme neuroborreliosis and 14-21 days for late Lyme neuroborreliosis.

- The outcome of treatment should be judged from the clinical manifestations.

The evidence suggests that chronic infection with Borrelia burgdorferi should not be assumed in patients with so-called PTLDS or PTLDS-like symptoms. Thus, these patients should not be treated with antibiotics $(\downarrow \downarrow)$. Rather, it is recommended that they undergo a symptom-oriented differential diagnostic evaluation and, where indicated, a corresponding, symptom-oriented treatment $(\uparrow \uparrow)$.

Note

The German Borreliosis Society (Deutsche Borreliose Gesellschaft, DBG) and three patient organizations (the German Borreliosis and FSME League - Borreliose und FSME Bund Deutschland [BFBD], The National Tick-Borne Disease Association - Bundesverband Zecken-Krankheiten e. V. [BZK], and the Action Committee against Tick-Borne Infections in Germany - Aktionsbündnis gegen zeckenübertragene Infektionen Deutschland e. V. [OnLymeAktion.org]) have issued dissenting statements, which are published as an appendix to the original guideline report. These four organizations did not approve the final version of the guideline.

\section{Conflict of interest statement}

Prof. Rauer owns stock in the ravo Diagnostik company (Freiburg), which manufactures serologic tests for the diagnosis of Lyme borreliosis. He has received payment from various judicial bodies and insurance companies for independent medical evaluations relating to the topic of this article. He has also received a lecture honorarium from Biogen.

Dr. Fingerle has received payment for three medicolegal evaluations relating to the topic of this article, honoraria and travel expenses for medical meetings from the Mikrogen, Diasorin, Seramun, and Pfizer companies, and travel expenses from Quality Control for Molecular Diagnostics.

Prof. Hunfeld has received payment for a medicolegal evaluation relating to the topic of this article.

The remaining authors state that they have no conflict of interest.

Manuscript submitted on 15 June 2018, revised version accepted on 19 July 2018.

Translated from the original German by Ethan Taub, M.D.

\section{References}

1. Dersch $\mathrm{R}$, Toews I, Sommer $\mathrm{H}$, et al.: Methodological quality of guidelines for management of Lyme neuroborreliosis. BMC Neurol 2015; 15: 242.

2. Dersch R, Freitag MH, Schmidt S, et al.: Efficacy and safety of pharmacological treatments for neuroborreliosis-protocol for a systematic review. Syst Rev 2014; 3: 117.

3. Dersch R, Freitag MH, Schmidt S, et al.: Efficacy and safety of pharmacological treatments for acute Lyme neuroborreliosis-a systematic review. Eur J Neurol 2015; 22: 1249-59.

4. Rauer S, Kastenbauer S, et al.: S3 Leitlinie Neuroborreliose. Deutsche Gesellschaft für Neurologie (ed.) 2018. Leitlinien für Diagnostik und Therapie in der Neurologie. www.dgn.org/leitlinien.

5. Oschmann P, Dorndorf W, Hornig C, et al.: Stages and syndromes of neuroborreliosis. J Neurol 1998; 245: 262-72. 
6. Hansen K, Lebech AM: The clinical and epidemiological profile of Lyme neuroborreliosis in Denmark 1985-1990. A prospective study of 187 patients with Borrelia burgdorferi specific intrathecal antibody production. Brain 1992; 115: 399-423.

7. Kaiser R: Variable CSF findings in early and late Lyme neuroborreliosis: a follow-up study in 47 patients. J Neurol 1994; 242: 26-36.

8. Djukic M, Schmidt-Samoa C, Lange $P$, et al:: Cerebrospinal fluid findings in adults with acute Lyme neuroborreliosis. J Neurol 2012; 259: 630-6.

9. Kristoferitsch W, Sluga E, Graf M, et al.: Neuropathy associated with acrodermatitis chronica atrophicans. Clinical and morphological features. Ann N Y Acad Sci 1988; 539: 35-45.

10. Kindstrand E, Nilsson BY, Hovmark A, et al.: Peripheral neuropathy in acrodermatitis chronica atrophicans-a late Borrelia manifestation. Acta Neurol Scand 1997; 95: 338-45.

11. Mygland A, Skarpaas T, Ljostad U: Chronic polyneuropathy and Lyme disease. Eur J Neurol 2006; 13: 1213-5.

12. Hess A, Buchmann J, Zettl UK, et al.: Borrelia burgdorferi central nervous system infection presenting as an organic schizophrenialike disorder. Biol Psychiatry 1999; 45: 795.

13. Christen HJ: Lyme neuroborreliosis in children. Ann Med 1996; 28 : 235-40.

14. Huppertz HI, Sticht-Groh V: Meningitis due to Borrelia burgdorferi in the initial stage of Lyme disease. Eur J Pediatr 1989; 148: 428-30.

15. Huppertz HI, Bartmann P, Heininger U, et al.: Rational diagnostic strategies for Lyme borreliosis in children and adolescents: recommendations by the Committee for Infectious Diseases and Vaccinations of the German Academy for Pediatrics and Adolescent Health. Eur J Pediatr 2012; 171: 1619-24.

16. Halperin JJ, Logigian EL, Finkel MF, Pearl RA: Practice parameters for the diagnosis of patients with nervous system Lyme borreliosis (Lyme disease). Quality Standards Subcommittee of the American Academy of Neurology. Neurology 1996; 46: 619-27.

17. Fingerle V, Eiffert $H$, Gessner $A$, et al.: Lyme borreliose. In: Podbielski A, Abele-Horn M, Hermann M, Kniehl E, Mauch H, Rüssmann $\mathrm{H}$ (eds.): MiQ - Qualitätsstandars in der mikrobiologisch-infektiologischen Untersuchung. $2^{\text {nd }}$ edition. München, Jena: Elsevier, Urban \& Fischer 2017.

18. Stanek G, Fingerle V, Hunfeld KP, et al.: Lyme borreliosis: clinical case definitions for diagnosis and management in Europe. Clin Microbiol Infect 2011; 17: 69-79.

19. Wilske B, Fingerle V, Schulte-Spechtel U: Microbiological and serological diagnosis of Lyme borreliosis. FEMS Immunol Med Microbiol 2007; 49: 13-21.

20. Ljostad U, Skarpaas T, Mygland A: Clinical usefulness of intratheca antibody testing in acute Lyme neuroborreliosis. Eur J Neurol 2007; 14: 873-6.

21. Reiber H, Peter JB: Cerebrospinal fluid analysis: disease-related data patterns and evaluation programs. J Neurol Sci 2001; 184: 101-22.

22. Kaiser R: Neuroborreliosis. J Neurol 1998; 245: 247-55.

23. Dessau RB, Fingerle V, Gray J, et al.: The lymphocyte transformation test for the diagnosis of Lyme borreliosis has currently not been shown to be clinically useful. Clin Microbiol Infect 2014; 20: 0786-7.

24. Lantos PM, Auwaerter PG, Wormser GP: A systematic review of Borrelia burgdorferi morphologic variants does not support a role in chronic Lyme disease. Clin Infect Dis 2014; 58: 663-71.
25. Jowett N, Gaudin RA, Banks CA, Hadlock TA: Steroid use in Lyme disease-associated facial palsy is associated with worse long-term outcomes. Laryngoscope 2017; 127: 1451-8.

26. Oksi J, Nikoskelainen J, Hiekkanen $\mathrm{H}$, et al.: Duration of antibiotic treatment in disseminated Lyme borreliosis: a double-blind, randomized, placebo-controlled, multicenter clinical study. Eur J Clin Microbiol Infect Dis 2007; 26: 571-81.

27. Pfister HW, Preac-Mursic V, Wilske B, et al.: Randomized comparison of ceftriaxone and cefotaxime in Lyme neuroborreliosis. J Infect Dis 1991; 163: 311-8.

28. Ogrinc K, Lusa L, Lotric-Furlan S, et al.: Course and outcome of early European Lyme neuroborreliosis (Bannwarth syndrome): clinical and laboratory findings. Clin Infect Dis 2016; 63: 346-53.

29. Kaiser R: [Clinical courses of acute and chronic neuroborreliosis following treatment with ceftriaxone]. Nervenarzt 2004; 75: 553-7.

30. Berglund J, Stjernberg L, Ornstein K, et al.: 5-y follow-up study of patients with neuroborreliosis. Scand J Infect Dis 2002; 34: 421-5.

31. Dersch R, Hottenrott T, Schmidt S, et al.: Efficacy and safety of pharmacological treatments for Lyme neuroborreliosis in children: a systematic review. BMC Neurol 2016; 16: 189.

32. Koedel U, Fingerle V, Pfister HW: Lyme neuroborreliosis-epidemiology, diagnosis and management. Nat Rev Neurol 2015; 11: 446-56.

33. Halperin JJ: Nervous system Lyme disease. Infect Dis Clin North Am 2015; 29: 241-53.

34. Feder HM, Jr., Johnson BJ, O'Connell S, et al.: A critical appraisal of "chronic Lyme disease". N Engl J Med 2007; 357: 1422-30.

35. Dersch R, Sommer H, Rauer S, Meerpohl JJ: Prevalence and spectrum of residual symptoms in Lyme neuroborreliosis after pharmacological treatment: a systematic review. J Neurol 2016; 263: 17-24

36. Klempner MS, Hu LT, Evans J, et al.: Two controlled trials of antibiotic treatment in patients with persistent symptoms and a history of Lyme disease. N Engl J Med 2001; 345: 85-92.

37. Fallon BA, Keilp JG, Corbera KM, et al.: A randomized, placebocontrolled trial of repeated IV antibiotic therapy for Lyme encephalopathy. Neurology 2008; 70: 992-1003

38. Krupp LB, Hyman LG, Grimson R, et al:: Study and treatment of post Lyme disease (STOP-LD): a randomized double masked clinical trial. Neurology 2003; 60: 1923-30.

39. Kaplan RF, Trevino RP, Johnson GM, et al.: Cognitive function in posttreatment Lyme disease: do additional antibiotics help? Neurology 2003; 60: 1916-22.

\section{Corresponding author}

Prof. Dr. med. Sebastian Rauer

Universitätsklinikum, Neurologie

Breisacher Str. 64,

9106 Freiburg, Germany

sebastian.rauer@uniklinik-freiburg.de

\section{- Supplementary material}

For eReferences please refer to: www.aerzteblatt-international.de/ref4518

eMethods, eFigures:

www.aerzteblatt-international.de/18m0751 
Supplementary material to:

\section{Lyme Neuroborreliosis}

by Sebastian Rauer, Stefan Kastenbauer, Volker Fingerle, Klaus-Peter Hunfeld, Hans-lko Huppertz,

and Rick Dersch for the guideline group

Dtsch Arztebl Int 2018; 115: 751-6. DOI: 10.3238/arztebl.2018.0751

\section{eReferences}

e1. Patel R, Grogg KL, Edwards WD, et al.: Death from inappropriate therapy for lyme disease. Clin Infect Dis 2000; 31: 1107-9.

e2. Holzbauer SM, Kemperman MM, Lynfield R: Death due to communityassociated clostridium difficile in a woman receiving prolonged antibiotic therapy for suspected lyme disease. Clin Infect Dis 2010; 51: 369-70.

e3. Marzec NS, Nelson C, Waldron PR, et al.: Serious bacterial infections acquired during treatment of patients given a diagnosis of chronic lyme disease-United States. MMWR Morb Mortal Wkly Rep 2017; 66: 607-9.

e4. Wilking $\mathrm{H}$, Stark K: Trends in surveillance data of human lyme borreliosis from six federal states in eastern Germany, 2009-2012. Ticks Tick Borne Dis 2014; 5: 219-24.

e5. Muller I, Freitag MH, Poggensee G, et al.: Evaluating frequency, diagnostic quality, and cost of lyme borreliosis testing in Germany: a retrospective model analysis. Clin Dev Immunol 2012; 2012: 595427.

e6. Kaiser R, Kern A, Kampa D, Neumann-Haefelin D: Prevalence of antibodies to borrelia burgdorferi and tick-borne encephalitis virus in an endemic region in southern Germany. Zentralbl Bakteriol 1997; 286: 534-41.

e7. Stanek G, Flamm H, Groh V, et al.: Epidemiology of borrelia infections in Austria. Zentralbl Bakteriol Mikrobiol Hyg A 1987; 263: 442-9.

e8. Wilking $\mathrm{H}$, Fingerle $\mathrm{V}$, Klier $\mathrm{C}$, et al.: Antibodies against borrelia burgdorferi sensu lato among adults, Germany, 2008-2011. Emerg Infect Dis 2015; 21: 107-10.

e9. Heininger U, Zimmermann T, Schoerner $C$, et al.: Zeckenstich und Lyme-Borreliose - Eine epidemiologische Untersuchung im Raum Erlangen. Monatsschrift Kinderheilkunde 1993; 141: 874-7.

e10. Maiwald M, Oehme R, March O, et al.: Transmission risk of borrelia burgdorferi sensu lato from Ixodes ricinus ticks to humans in southwest Germany. Epidemiol Infect 1998; 121: 103-8.

e11. Paul H, Gerth HJ, Ackermann R: Infectiousness for humans of Ixodes ricinus containing borrelia burgdorferi. Zentralblatt fur Bakteriologie, Mikrobiologie, und Hygiene. Series A, Medical microbiology, infectious diseases, virology, parasitology 1987; 263: 473-6.

e12. Henningsson AJ, Malmvall BE, Ernerudh J, et al.: Neuroborreliosis an epidemiological, clinical and healthcare cost study from an endemic area in the south-east of Sweden. Clin Microbiol Infect 2010; 16: 1245-51.

e13. Hassler D, Zoller L, Haude $M$, et al.: [Lyme borreliosis in an endemic region in Europe. Prevalence of antibodies and clinical spectrum]. Dtsch Med Wochenschr 1992; 117: 767-74.

e14. Pasareanu AR, Mygland A, Kristensen O: A woman in her 50 s with manic psychosis. Tidsskr Nor Laegeforen 2012; 132: 537-9.

e15. Roelcke U, Barnett W, Wilder-Smith E, et al.: Untreated neuroborreliosis: Bannwarth's syndrome evolving into acute schizophrenia-like psychosis. A case report. J Neurol 1992; 239: 129-31.

e16. Markeljevic J, Sarac H, Rados M: Tremor, seizures and psychosis as presenting symptoms in a patient with chronic lyme neuroborreliosis (LNB). Coll Antropol 2011; 35, Suppl 1: 313-8. e17. Csaszar T, Patakfalvi A: [Differential diagnostic problems in lyme disease (Borrelia infection resulting in acute exogenous psychosis)]. Orv Hetil 1994; 135: 2269-71.

e18. Wittwer B, Pelletier S, Ducrocq X, et al.: Cerebrovascular events in lyme neuroborreliosis. J Stroke Cerebrovasc Dis 2015; 24: 1671-8.

e19. Zajkowska J, Garkowski A, Moniuszko A, et al.: Vasculitis and stroke due to lyme neuroborreliosis-a review. Infect Dis (Lond) 2015; 47: $1-6$

e20. Schmutzhard E, Willeit J, Gerstenbrand F: Meningopolyneuritis Bannwarth with focal nodular myositis. A new aspect in lyme borreliosis. Klin Wochenschr 1986; 64: 1204-8.

e21. Reimers $C D$, de Koning J, Neubert U, et al.: Borrelia burgdorfer myositis: report of eight patients. J Neurol 1993; 240: 278-83

e22. Wilke M, Eiffert $\mathrm{H}$, Christen HJ, Hanefeld F: Primarily chronic and cerebrovascular course of lyme neuroborreliosis: case reports and literature review. Arch Dis Child 2000;83:67-71.

e23. Nordberg M, Forsberg P, Nyman D, et al.: Can ELISPOT be applied to a clinical setting as a diagnostic utility for neuroborreliosis? Cells 2012; 1: 153-67.

e24. Marques A, Telford SR, III, Turk SP, et al.: Xenodiagnosis to detect borrelia burgdorferi infection: a first-in-human study. Clin Infect Dis 2014; 58: 937-45

e25. Bockenstedt LK, Radolf JD: Xenodiagnosis for posttreatment lyme disease syndrome: resolving the conundrum or adding to it? Clin Infect Dis 2014; 58: 946-8

e26. Hartmann F, Mueller-Marienburg H: Indirekter Neurotoxinnachweis durch den „Visual Contrast Sensitivity“-Test bei Patienten mit einer chronischen Borreliose. Die Medizinische Welt - aus der Wissenschaft in die Praxis 2003; 54: 248-51.

e27. Stricker RB, Winger EE: Decreased CD57 lymphocyte subset in patients with chronic lyme disease. Immunology Letters 2001; 76 43-8.

e28. Smit PW, Kurkela S, Kuusi M, Vapalahti O: Evaluation of two commercially available rapid diagnostic tests for lyme borreliosis. Eur J Clin Microbiol Infect Dis 2015; 34: 109-13

e29. Klempner MS, Baker PJ, Shapiro ED, et al.: Treatment trials for post-lyme disease symptoms revisited. Am J Med 2013; 126: 665-9.

e30. Brouwers MC, Kho ME, Browman GP, et al.: AGREE II: advancing guideline development, reporting, and evaluation in health care. Prev Med 2010; 51: 421-4

e31. Mygland A, Ljostad U, Fingerle V, et al.: EFNS guidelines on the diagnosis and management of European lyme neuroborreliosis. Eur J Neurol 2009

e32. Halperin JJ, Shapiro ED, Logigian E, et al.: Practice parameter: treatment of nervous system lyme disease (an evidence-based review): report of the quality standards subcommittee of the American Academy of Neurology. Neurology 2007; 69: 91-102.

e33. Rauer S, Kaiser R, Kölmel HW, et al.: Neuroborreliose. In: Diener $\mathrm{HC}$, Weimar C (eds.): Leitlinien für Diagnostik und Therapie in de Neurologie. Stuttgart, New York: Georg Thieme Verlag 2012: 513-22.

e34. Balshem $\mathrm{H}$, Helfand M, Schunemann HJ, et al.: GRADE guidelines: 3. rating the quality of evidence. J Clin Epidemiol 2011; 64: 401-6. 


\section{eMETHODS SECTION}

\section{Supplementary information on methods}

There were 29 members in the interdisciplinary guideline group. The Consensus Committee consisted of delegates from 19 medical-scientific specialty societies, all of which are member societies of the Association of Scientific Medical Societies in Germany (AWMF), as well as the Paul Ehrlich Society, the Robert Koch Institute, the German Borreliosis Society, and three patient organizations (eBox).

A panel of five expert scientists, including one representative each from Austria and Switzerland, all of whom had previously been coauthors of the S1 guideline on Lyme neuroborreliosis, served in an advisory capacity. The guideline was developed in five consensus conferences with formal consensus determination under the moderation of the AWMF (Prof. Ina Kopp). In an initial constituting consensus conference on 11 February 2014, votes were taken on the method of proceeding and on the key questions to be answered. A vote was taken on the final manuscript in the fifth consensus conference on 9 February 2017.

The systematic search of the literature for existing guidelines yielded eight guidelines on the topic of Lyme neuroborreliosis. None of them had a methodological precision score above $50 \%$ in the AGREE II rating scheme (e30). In consequence, the recommendations found in these guidelines could not be adopted without further investigation, and independent literature searches were performed for the creation of this guideline (1).

The systematic literature search and evaluation were conducted by the German Cochrane Center in Freiburg (Cochrane Deutschland) under the leadership of Rick Dersch. The PICO scheme was applied $(\mathrm{P}=$ patient characteristics, clinical problem; $\mathrm{I}=$ intervention; $\mathrm{C}=$ comparison [against alternatives]; $\mathrm{O}=$ outcome [endpoint criteria]).

On the basis of the systematic literature searches, and with additional reference to the $\mathrm{S} 1$ guideline on Lyme neuroborreliosis, a draft manuscript was created that was then revised by the consulting expert group in a modified Delphi procedure, submitted to a formal consensus process in the consensus conferences, accordingly adapted, and, finally, voted on.

\section{Case definition}

Infectious disease specialists consider the microbiological demonstration of the reponsible pathogen to be the gold standard for the definition of an infectious disease. However, pathogen detection in the CSF has only 10-30\% sensitivity in the case of Lyme neuroborreliosis, and therefore a consensus was obtained for defining the disease according to diagnostic criteria based on a combination of typical clinical manifestations, CSF findings, and Borrelia serology; these were derived from suggestions found in earlier reviews and the existing guidelines (18, 22, e31-e33). This definition distinguishes between possible, probable, and definite Lyme neuroborreliosis (cf. printed version).

\section{Systematic literature search}

A systematic literature search was carried out to assess pharmacotherapy for Lyme neuroborreliosis (3). The retrieved publications were then assessed and summarized. The search was carried out in three literature databases:

- Medline (via Ovid),

- Embase (via Scopus),

- and the Cochrane Central Register of Controlled Trials.

The searching strategy in each database is listed in the guideline report.

\section{The treatment of Lyme neuroborreliosis in adults}

A flowchart showing the included studies (in accordance with the PRISMA statement) is found in the Figure (3).

\section{Assessment of the evidence}

The quality of the individual randomized and controlled trials (RCT) was studied and assessed with the aid of the Risk of Bias Tool of the Cochrane Collaboration (www.handbook.cochrane. org). The quality of the nonrandomized studies (cohort studies) was assessed with the ACROBAT-NRSI Tool of the Cochrane Collaboration (www.riskofbias.info). The totality of 
the endpoint-related evidence was assessed with the GRADE method (Grading of Recommendations Assessment, Development and Evaluation) (e34, 4).

\section{Consideration of benefit, side effects, and relevant endpoints}

During the creation of the sytematic review, no robust data on placebo-controlled treatments were found to be available (3). There are, however, evaluable studies comparing different classes of antibiotics with respect to their efficacy and side-effect profiles. These are discussed in Chapter 5 of the original guideline (4), and the corresponding studies are summarized in tabular fashion in Appendices 3, 4, and 5. Appendix 8 of the original guideline contains a description of the evidence assessment of these studies according to the GRADE scheme.

\section{Formulation of recommendations and assignment of evidence and/or recommendation grades}

For each treatment recommendation, a corresponding background text was provided, indicating the evidence grade as derived from the systematic review (2, e30, e38). The evidence was classified as specified in the British NICE-SCIE guideline (4).

\section{Standardization of recommendations}

Uniform formulations were used in order to standardize the recommendations in the guideline. The scale of recommendation strengths was as follows:

- strong recommendation: German word „,soll“ $\uparrow \uparrow$

- recommendation: German word ,sollte“ $\uparrow$

- open recommendation: German phrase „kann erwogen werden“ (may be considered) $\leftrightarrow$

- recommendation against an intervention: German phrase ,sollte nicht“ $\downarrow$

- strong recommendation against an intervention: German phrase ,soll nicht“ $\downarrow \downarrow$

The recommendation grades were assigned in the formal consensus conferences. Aside from the quality of the available evidence, the following criteria were also explicitly taken into account (4):

- consistency of study findings, directness of evidence, precision of effect estimators (GRADE profiles)

- clinical relevance of the endpoints (outcomes) and effect strengths

- ratio of benefit to harm

- legal considerations (approval status)

- patient preferences

- real-world implementability.

Because of the aspects of consensus-finding mentioned above, the recommendation grade was higher or lower than the corresponding evidence grade in a small number of cases. 


\section{eFIGURE 1}

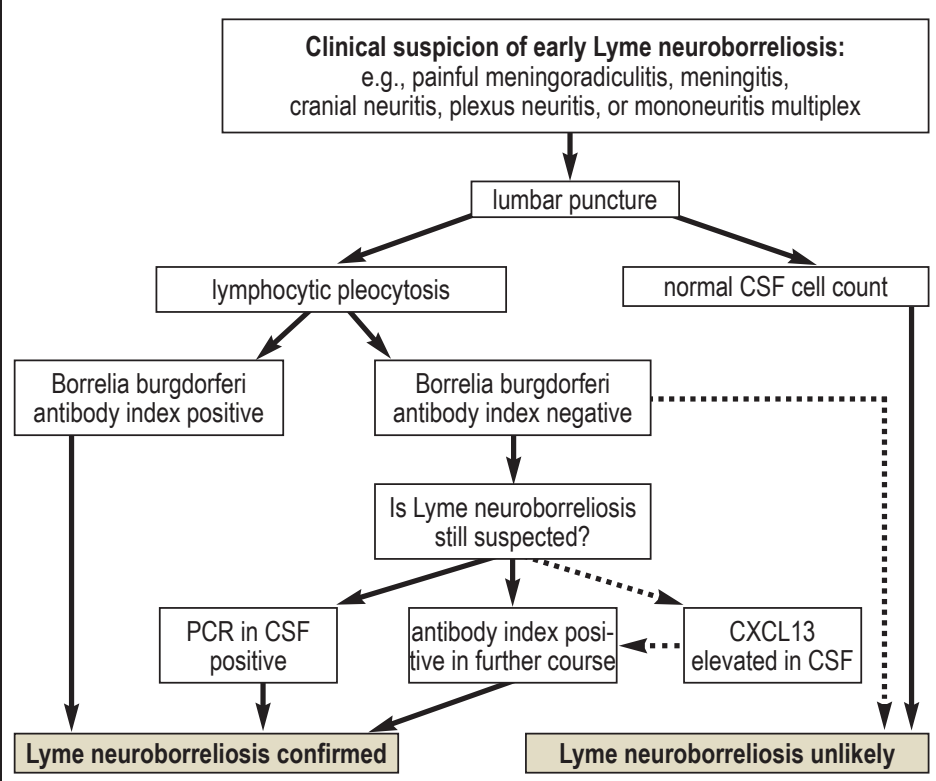

Diagnostic algorithm

for early Lyme neuroborreliosis (4)

$\mathrm{PCR}$, polymerase chain reaction;

CXCL, C-X-C motif chemokine ligand

\section{eFIGURE 2}

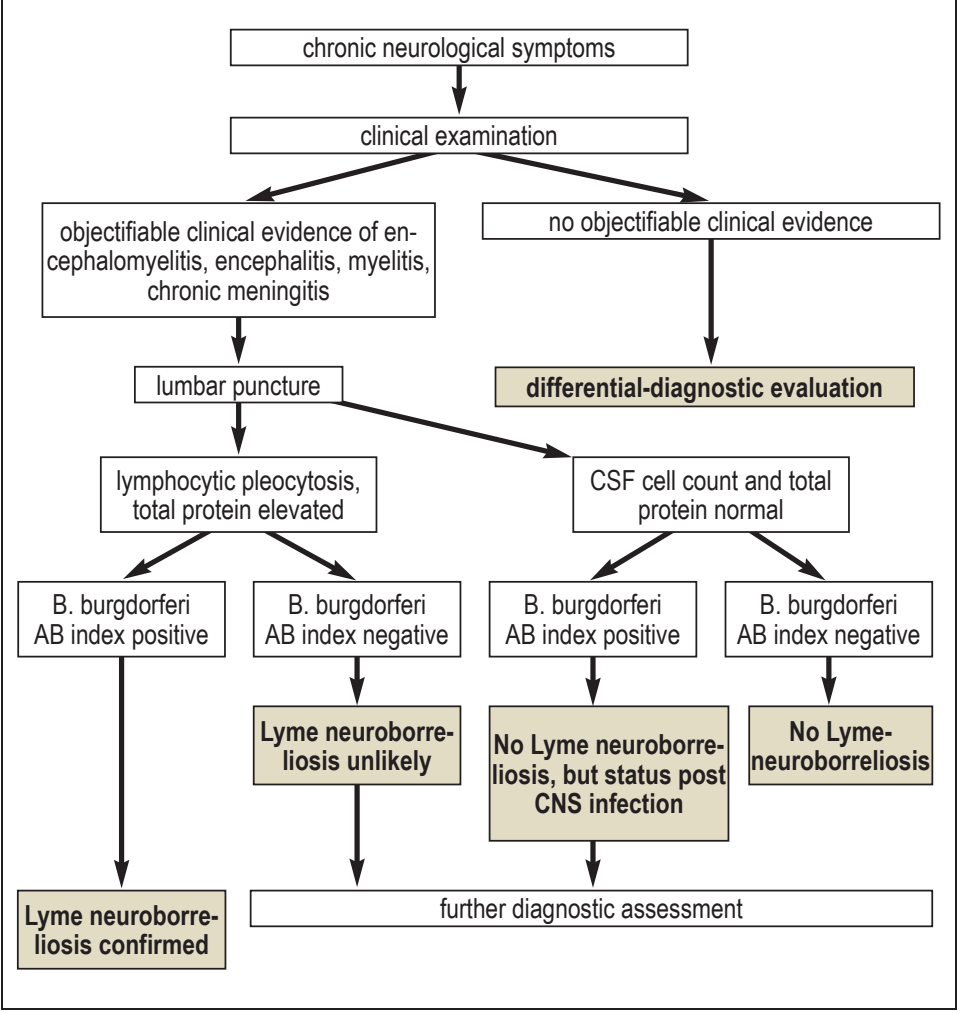

\section{Diagnostic algorithm}

for late Lyme neuroborreliosis (4).

AB, antibody; B., Borrelia 


\section{Contributors and collaborators*}

\section{Steering Committee}

Prof. Dr. med. Sebastian Rauer (head)—-coordinator in collaboration with Dr. med. Rick Dersch*

German Society for Neurology (Deutsche Gesellschaft für Neurologie, DGN)

PD Dr. med. Stefan Kastenbauer*-deputy coordinator

German Society for Neurology (Deutsche Gesellschaft für Neurologie, DGN)

Prof. Dr. med. Heidelore Hofmann*-coordinator

German Dermatological Society (Deutsche Dermatologische Gesellschaft, DDG)

Dr. med. Volker Fingerle*

German Society for Hygiene and Microbiology (Deutsche Gesellschaft für Hygiene und Mikrobiologie, DGHM)

Prof. Dr. med. Hans-lko Huppertz*

German Society for Child and Adolescent Medicine (Deutsche Gesellschaft für Kinder und Jugendmedizin, DGKJ) and

German Society for Pediatric Infectious Disease (Deutsche Gesellschaft für Pädiatrische Infektiologie, DGPI)

Prof. Dr. med. Klaus-Peter Hunfeld*

German Society for Clinical Chemistry and Laboratory Medicine (Deutsche Gesellschaft für klinische Chemie und Laboratoriumsmedizin, DGKL) and INSTAND e. V.

Prof. Dr. med. Andreas Krause*

German Society for Rheumatology (Deutsche Gesellschaft für Rheumatologie, DGRh)

Prof. Dr. med. Bernhard Ruf*

German Society for Infectious Disease (Deutsche Gesellschaft für Infektiologie, DGI)

\section{Consensus Committee}

(The Steering Committee is also a component of the Consensus Committee.)

Prof. Dr. med. Karl Bechter*

German Society for Psychiatry, Psychotherapy, and Nervous Diseases (Deutsche Gesellschaft für Psychiatrie, Psychotherapie und Nervenheilkunde, DGPPN)

PD Dr. med. Walter Berghoff*

German Borreliosis Society (Deutsche Borreliose Gesellschaft, DBG)

Ursula Dahlem*

Action Committee against Tick-Borne Infections in Germany (Aktionsbündnis gegen zeckenübertragene Infektionen Deutschland e. V.

[OnLyme-Aktion.org])

Ute Fischer*

German Borreliosis and FSME League (Borreliose und FSME Bund Deutschland, BFBD)

Prof. Dr. med. Michael H. Freitag*

German College of General Practitioners and Family Physicians (Deutsche Gesellschaft für Allgemeinmedizin und Familienmedizin, DEGAM)

PD Dr. med. Gudrun Gossrau*

German Pain Society (Deutsche Schmerzgesellschaft e. V., DGSS)

Prof. Dr. med. Gerd Gross*

Paul Ehrlich Society for Chemotherapy (Paul Ehrlich Gesellschaft für Chemotherapie, PEG)

Prof. Dr. med. Rainer Müller*

German Society for Otorhinolaryngology and Head and Neck Surgery (Deutsche Gesellschaft für Hals-Nasen-Ohren-Heilkunde,

Kopf- und Hals-Chirurgie, DGHNO-KHC)

Prof. Dr. med. Mathias Pauschinger*

German Society for Cardiology—Cardiac and Circulatory Research (Deutsche Gesellschaft für Kardiologie - Herz und Kreislaufforschung e. V., DGK)

Prof. Dr. med. Monika A. Rieger*

German Society for Occupational and Environmental Medicine (Deutsche Gesellschaft für Arbeitsmedizin und Umweltmedizin, DGAUM)

Prof. Dr. med. Rainer Schäfert* (until 31 March 2017)

Dr. Jonas Tesarz* (From 1 April 2017)

German Society for Psychosomatic Medicine and Medical Psychotherapy (Deutsche Gesellschaft für Psychosomatische Medizin und Ärztliche

Psychotherapie, DGPM)

and German College of Psychosomatic Medicine (Deutsches Kollegium für Psychosomatische Medizin, DKPM) 
Christel Schmedt*

National Tick-Borne Disease Association (Bundesverband Zecken-Krankheiten e. V., BZK)

Prof. Dr. med. Stephan Thurau*

German Ophthalmological Society (Deutsche Ophthalmologische Gesellschaft e. V., DOG)

Prof. Dr. rer. nat. Reinhard Wallich*

German Society for Immunology (Deutsche Gesellschaft für Immunologie, DGfl)

Dr. Hendrik Wilking*

Robert Koch Institute (RKI)

\section{Moderation}

Prof. Dr. Ina Kopp

Association of Scientific Medical Societies in Germany (Arbeitsgemeinschaft der Wissenschaftlichen Medizinischen Fachgesellschaften, AWMF)

\section{Consulting Experts}

Prof. Dr. R. Kaiser*, Neurologische Klinik, Helios Klinikum Pforzheim

Prof. Dr. H. W. Kölmel*, formerly Klinik für Neurologie, Helios Klinikum Erfurt

Prof. Dr. H. W. Pfister*, Neurologische Klinik, Ludwig-Maximilians-Universität, Munich

For the Austrian Society for Neurology (Österreichische Gesellschaft für Neurologie):

Prof. Dr. E. Schmutzhard*, Universitätsklinik für Neurologie - NICU, Medizinische Universität Innsbruck, Austria

For the Swiss Neurological Society (Schweizerische Neurologische Gesellschaft):

Prof. Dr. M. Sturzenegger*, Neurologische Universitätsklinik, Inselspital, Universität Bern, Switzerland

\section{Issuing body}

Guidelines Committee of the German Society for Neurology

The boards of directors of the following societies and organizations approved this guideline:

German Society for Neurology (DGN)

German Dermatological Society (DDG)

German College of General Practitioners and Family Physicians (DEGAM)

German Society for Occupational Medicine (DGAM)

German Society for Otorhinolaryngology and Head and Neck Surgery (DGHNOKHC)

German Society for Hygiene and Microbiology (DGHM)

German Society for Immunology (DGfl)

German Society for Infectious Diesease (DGI)

German Society for Cardiology - Cardiac and Circulatory Research (DGK)

German Society for Child and Adolescent Medicine (DGKJ)

German Society for Clinical Chemistry and Laboratory Medicine (DGKL) and INSTAND e. V.

German Society for Pediatric Infectious Disease (DGPI)

German Society for Psychiatry, Psychotherapy, and Nervous Diseases (DGPPN)

German Society for Psychosomatic Medicine and Medical Psychotherapy (DGPM)

and German College of Psychosomatic Medicine (DKPM)

German Society for Rheumatology (DGRh)

German Pain Society (DGSS)

German Ophthalmological Society (DOG)

Paul Ehrlich Society for Chemotherapy (PEG)

Robert Koch Institute (RKI)

The following organizations did not approve this guideline:

German Borreliosis Society (DBG)

Action Committee against Tick-Borne Infections in Germany (OnLyme-Aktion)

German Borreliosis and FSME League (BFBD)

National Tick-Borne Disease Association (BZK) 